\title{
Anàlisi crítica d'aplicacions de lectura per a infants: paràmetres i indicadors
}

\author{
Maria Peris Bixquert \\ Universitat de València
}

(Text rebut el 25 de juny del 2017; acceptat el 17 d'abril de 2018; versió final el 29 de setembre del 2018)

DOI: http://doi.org/10.5565/rev/jt13.734

\begin{abstract}
Resum: Les aplicacions de lectura digital infantil han evolucionat considerablement al llarg dels últims anys. Tanmateix, segueixen sent les grans oblidades en informes i estadístiques sobre la producció editorial i més encara dins del sector digital, cosa que origina un fenomen d'infoxicació en què el mediador es troba amb pocs criteris que faciliten la selecció d'aquest nou tipus de continguts. Aquesta investigació presenta els resultats de l'anàlisi de tretze aplicacions de lectura en les seues dimensions de forma i contingut. Alhora, s'hi observen trets com ara el mode d'adquisició, la privacitat, l'organització de continguts o la personalització. Finalment, reflexionarem sobre l'adequació dels criteris, atès que l'anàlisi de les tretze aplicacions ha mostrat com els paràmetres no analitzen amb la profunditat exigida el grau de plasticitat que poden arribar a tenir-ne les aplicacions i la facilitat per a esdevenir literatura digital.
\end{abstract}

Paraules clau: lectura digital infantil, aplicacions de lectura, indicadors d'avaluació d'apps, avaluació d'aplicacions de lectura

Resumen: Las aplicaciones de lectura digital infantil han evolucionado considerablemente a lo largo de los últimos años. Aún así, siguen siendo las grandes olvidadas en informes y estadísticas sobre la producción editorial y más todavía dentro del sector digital, cosa que origina un fenómeno de infoxicación en que el mediador se encuentra con pocos criterios que facilitan la selección de este nuevo tipo de contenidos. Esta investigación presenta los resultados del análisis de trece aplicaciones de lectura en sus dimensiones de forma y contenido. A la vez, se observan rasgos como el modo de adquisición, la privacidad, la organización de contenidos o la personalización. Finalmente, reflexionaremos sobre la adecuación de los criterios, dado que el análisis de las trece aplicaciones ha mostrado cómo los parámetros no analizan con la profundidad exigida el grado de plasticidad que pueden llegar a tener las aplicaciones y su facilidad para convertirse en literatura digital.

Palabras clave: lectura digital infantil, aplicaciones de lectura, indicadores de evaluación de apps, avaluación de aplicaciones de lectura

\begin{abstract}
Children's digital literature apps have been considerably developed in past years. Even so, editorial production is forgotten in reports and statistics, especially in the digital sector. This fact generates a phenomenon called information overload in which the intermediary has difficulties finding guidelines which make the selection of these new type of contents easy. This research shows the results of the analysis of thirteen reading apps for form and content. At the same time, we can observe traits like the method of acquisition, privacy, the contents' organization or personalization. Finally, we will reflect on the appropriateness of the criteria, since the analysis of the thirteen apps has shown how the parameters do not analyze in depth the degree of plasticity of the apps and their facility for turning into digital literature.
\end{abstract}

Keywords: children's digital literature, reading apps, apps evaluation indicators, reading apps assessment. 


\section{Les aplicacions de lectura en l'entorn digital}

Des del seu origen, Internet ha significat una autèntica revolució digital. Les noves tecnologies han desembocat en un nou gènere de cultura que s'obri pas i no pot ser consumida sense les noves eines: ordinadors, telèfons intel·ligents, tauletes, llibres electrònics... El ciberespai atorga una certa llibertat de producció i divulgació de textos literaris gràcies a la seua pròpia essència basada en contínues transformacions de contingut a l'abast de tots els públics. Enmig d'aquest context trobem que la literatura infantil, tot i ocupar un lloc privilegiat dins del mercat editorial, segueix sent la gran oblidada en informes, enquestes o anàlisis de mercat a causa del desconeixement $i$ la por social a aquest entorn, el que suposa que no comptem amb suficients dades per a estudiar amb profunditat el comportament de la seua edició digital.

D'aquesta manera, segons l'informe El sector del libro en España (2013-2015) realitzat pel Observatorio de la Lectura i el Ministerio de Educación Cultura y Deportes (2015) la producció digital creix lentament fins a l'any 2010, moment en què es posen en marxa diversos projectes que originen l'augment de vendes dels dispositius electrònics.

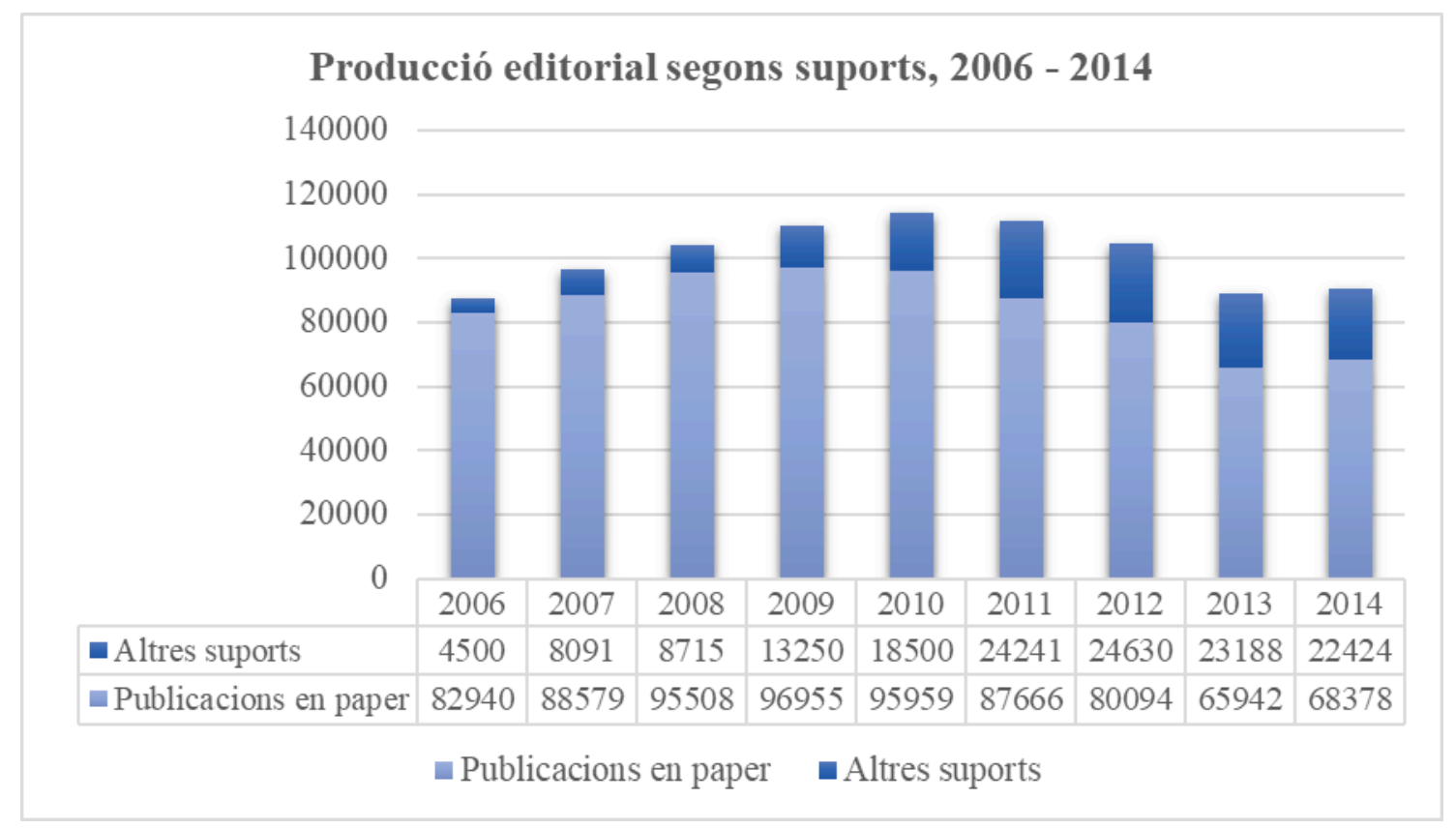

Figura 1. Producció editorial segons suports. Font: Elaboració pròpia a partir d'«Informe del sector del libro en España (2013-2015)», Observatorio de la Lectura y del Libro (2015) 
En la Figura 1 podem observar com aquest comerç avança lentament fins que els anys 2013 i 2014 hi ha una davallada d'un 1,9\% respecte dels anys anteriors. Ara bé, tot i aquesta davallada, la producció de literatura infantil i juvenil augmenta lentament i ara 55 dels 250 títols registrats diàriament a l'Estat espanyol són en format digital. Així doncs, la literatura digital avança i ens condueix a una sèrie de cruïlles desafiants sobre el present i, sobretot, el futur. És en aquest context que situem el gènere dels llibres app, definits per Sanz Pilar i García-Rodríguez (2014, p. 2) com a:

Programas informáticos pero ligados a la lectura de un título determinado y que se adquieren de forma independiente en las plataformas de distribución y venta. Es decir, que todas las aplicaciones de lectura incluyen libros apps, pero no todos los libros apps forman parte de una aplicación de lectura.

Al seu torn, la suma de diferents llibres app en una mateixa aplicació esdevé una aplicació de lectura, que en paraules de Gómez-Díaz i Cordón-García $(2015, \S 1)$ és:

Programa informático que permite la gestión de contenidos, principalmente textuales, y el acceso a los mismos, así como la interacción con el lector usuario, facilitando en la mayor parte de los casos la adaptación del contenido (cambio de tipo y tamaño de la letra, espaciado, color de fondo...) para que pueda ser leído en un dispositivo móvil de lectura.

Trobem un nou tipus de literatura on la suma de diversos mitjans amplifica la narrativa gràcies a noves tècniques com la transmediació, storytelling o la realitat augmentada que aconsegueixen crear una literatura amb un gran potencial, capaç de viatjar en molts formats diferents per adaptar-se al nou entorn digital. Les aplicacions de lectura esdevenen un nou contingut enriquit que combina la informació textual amb la informació multimèdia. Com a resultat, s'hi potencien aprenentatges paral·lels als de la literatura analògica (vegeu Flewitt, Messer i Kucirkova, 2015; Aliagas i Margallo 2014, 2015) en què observen els patrons lectors digitals en tres famílies diferents a partir de la qual cosa posen en relleu els canvis que han sorgit en la perspectiva lectora de les famílies i el procés d'absorció ficcional que hi té lloc (Aliagas Marín i Margallo 2015, p. 166), gràcies al qual els infants queden captivats per la metaliteratura de les apps $i$ després de la lectura, aconsegueixen generar un discurs i una reinterpretació pròpia a partir del que han llegit.

Ara bé, dins de la immensitat del ciberespai, també apareix un nou fenomen anomenat infoxicació, que Báez Montero i Suárez Rodríguez (2011, p. 117) defineixen com «la sobresaturación de información, ruido-interferencia, la cual incluso puede llegar a generar angustia en el usuario por no sentirse en condiciones de encontrar la 
información buscada» i és que aquest nou gènere de lectura en pantalla, no compta amb uns criteris i paràmetres definits que ajuden a orientar-ne els consumidors com els que sí té la lectura en paper (Lluch, 2010 i Colomer, 2010). És per això que les aplicacions ens plantegen tota una mena d'interrogants entre els mediadors involucrats en la lectura: famílies, professors, bibliotecaris. Amb la intenció de facilitar-ne aquesta tasca, necessitem crear i establir termes i categories específiques per a la selecció de la literatura infantil i juvenil digital, a més de concretar un protocol d'avaluació estàndard per a l'elecció i per a la posterior adquisició d'aquests nous tipus de continguts digitals, ja que només així el lector i usuari serà capaç de distingir les millors aplicacions. Com remarquen Correro i Real (2014, p. 41):

El paper de la mediació en l'accés dels petits lectors a la producció digital és com a mínim tan essencial com el que té respecte de la literatura en paper; potser més, fins $\mathrm{i}$ tot, tenint en compte, d'una banda, l'estat embrionari de la producció i la seva qualitat literària limitada en molts casos, i, de l'altra, la multimodalitat dels textos electrònics $i$ els seus possibles efectes en l'experiència de lectura.

Meyers, Zaminpaima i Fredero (2014, p. 918) proposen un nou esquema nou esquema de llibre digital textual establert per a les aplicacions de lectura i llibres app (Figura 2). Aquest esquema significa un autèntic repte tant per als desenvolupadors com per a les empreses editorials que proposen aquest nou tipus de lectura. Tots ells han de tindre en compte la plasticitat del cervell dels consumidors, a més de tindre cura dels alts nivells d'interactivitat que ofereix aquesta nova proposta: tecnologia $3 \mathrm{D}$, realitat augmentada, accés a les xarxes socials, la possibilitat de personalització dels continguts, missatgeria i, especialment, la gamificació, que n'esdevindrà la base. 


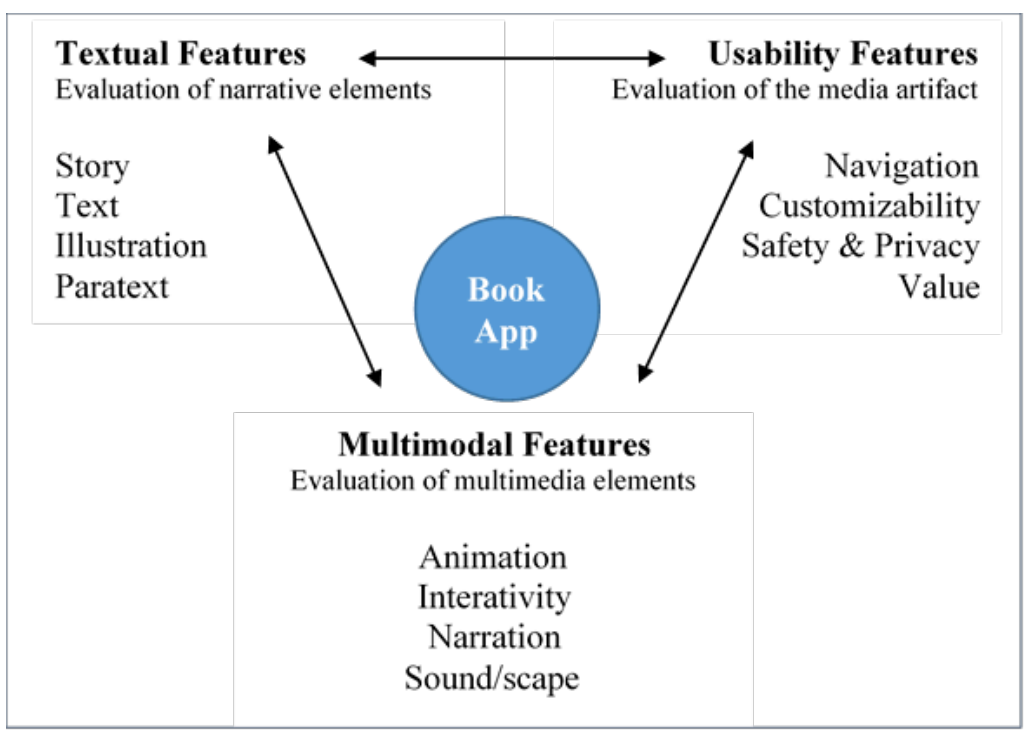

Figura 2. Book App. Font: Meyers, Zaminpaima i Fredero (2014, p. 918)

Com a conseqüència, s'hi genera un nou lector-usuari. Teixes (2014, p. 23) diferencia dos nous tipus de lectors: 1'«explorador o explorer» que interactua gaudint dels enigmes i secrets que hi troba per tal d'avançar i l'«aconseguidor o achiever» que comença a llegir amb uns objectius fixats: completar-ne la lectura per tal de ser recompensat amb les tasques i reptes que se li plantegen al llarg de la història. Així, les dinàmiques de recompensa, estatus, premis, autoexpressió, competició o diversió són rellevants per atraure els joves lectors, ja que durant la lectura, entren en bucles d'activitat (Teixes, 2014, p. 81) dins dels quals se centrarà tota la seua atenció mitjançant tres fases connectades entre elles: motivació, acció i feedback o interacció. Gràcies a aquests bucles s'aconsegueix la finalitat d'aquest nou gènere: trencar barreres i apropar la literatura als infants. Amb tot l'esmentat anteriorment, ens trobem que també apareix un nou paradigma lector que dinamita el model proposat fins al moment, el qual queda desplaçat en aquesta proposta lectora, ja que en paraules de Turrión (2015, p. 89):

Regarding fictional experience variations, this essay qüestions wheter the Integration of interactivity, specific playful elements or fílmic nodes of representation in digital stories have really removed the tradicional reading activity from its central position. [...] Interactive studies have shown the insufficiency of the narratological model for the analysis of Works that include the reader's participation proposal.

La Figura 2, juntament amb les propostes de lector digital de Teixes, ens deixa entreveure tres rols diferents en la psicologia d'aquest nou model de lector: l'estructura, 
la sistematització i la intuïció. I és que les aplicacions «analitzen descobriments i vivències més sensorials en la mesura que requereixen l'exercici simultani de la vista, l'oïda i el tacte» (Correro i Real, 2014, p. 40). Per això, tendim a pensar en la noció de nadius digitals que Celaya (2014, p. 14) defineix com:

Jóvenes capaces de estar en todo a la vez en su hiperconexión, trabajar con el ordenador actualizar perfiles en sus redes sociales, contestar por el móvil, escuchar música y hacer deberes, casi todo a la vez.

Tot i això, no podem oblidar que les aplicacions de lectura i llibres app, a més d'estar adreçades a joves que parteixen d'una alfabetització digital amb coneixements, competències i capacitats cognitives adaptades, exigeix la mateixa concentració que la lectura en paper, $\mathrm{i}$ «fer més coses no implica comprendre millor» (Lluch, 2011, 2015). Ara bé, cal tindre cura amb el concepte «nadiu digital», ja que, si bé és cert que els infants actuals són nadius digitals, també és cert que són poc competents. Per això optem pel terme «orfes digitals» (Roca, 2012) que ressalta la mediació que necessiten per a evitar naufragar en la xarxa.

\section{Punts clau en l'anàlisi d'apps}

Tenint en compte tot l'esmentat anteriorment, utilitzem com a protocol d'anàlisi la proposta de García-Rodríguez i Gómez-Díaz (2015) que permet examinar els paràmetres clau en llibres app i aplicacions de lectura: el dispositiu, el sistema operatiu, el preu i models de negoci, la metodologia, les tendències i la seguretat, la qual, alhora es divideix en personalització, gamificació i interacció (Figura 3). Aquests paràmetres es classifiquen en dues dimensions: forma, quan parlem de les qüestions formals i del suport per a llegir i contingut. Aquest protocol comparteix l'afirmació de Correro i Real (2014, pp. 40-41) que les aplicacions i dispositius serveixen «per acompanyar els infants en l'experiència de lectura (ara digital), guiar-lo en la comprensió del text, evitar el conflicte [...], contrarestar la dispersió [...] i minimitzar els usos purament lúdics dels dispositius». 


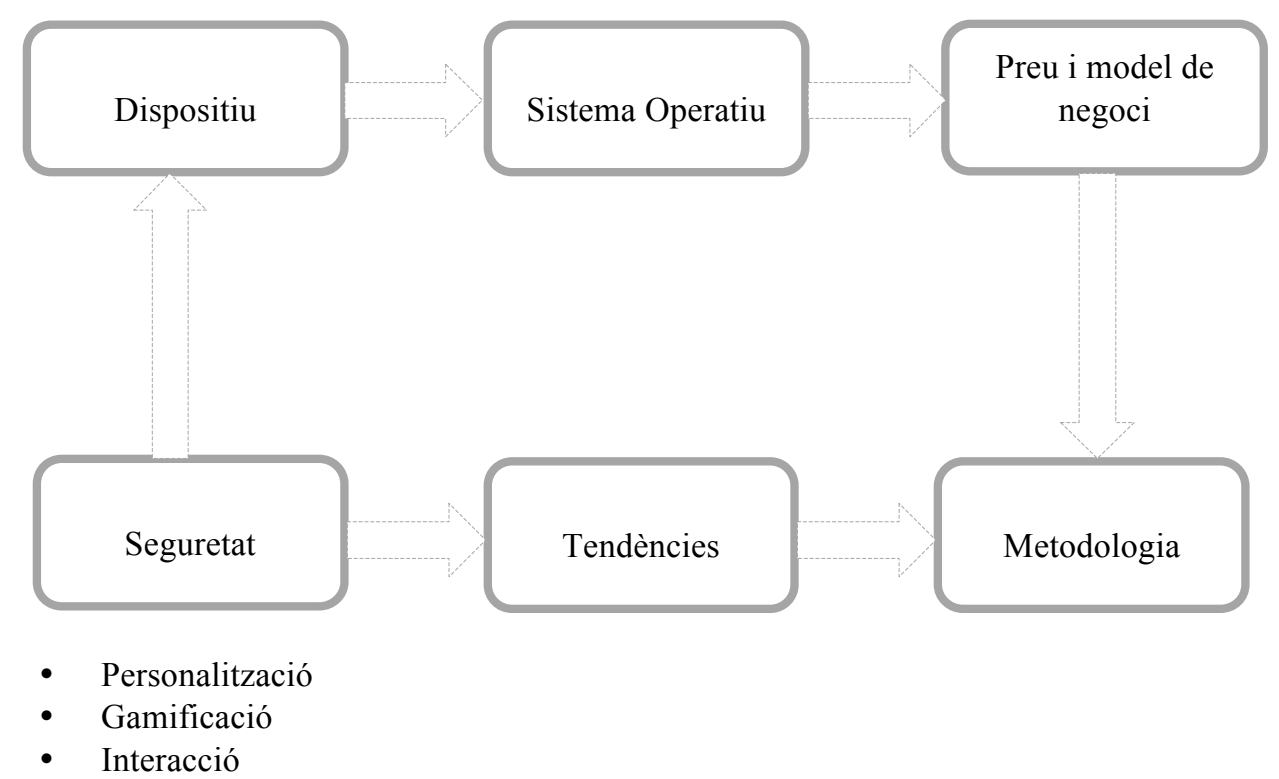

Figura 3. Punts clau en l'anàlisi d'aplicacions i llibres app. Font: Elaboració pròpia a partir de «Lectura digital infantil. Dispositivos, aplicacions i contenidos» de García Rodríguez i Gómez-Díaz (2016)

La dimensió forma conté huit paràmetres que presenta tot sovint amb les reflexions plantejades al llarg de l'anàlisi de les aplicacions escollides:

1. Disponibilitat $i$ accés a l'aplicació. Tindrem en compte els sistemes operatius en què podem trobar les aplicacions i la possibilitat de descàrrega tant a la botiga d'aplicacions com als webs dels desenvolupadors, també valorarem positivament la diversitat lingüística que ofereixen.

2. Adquisició. A la botiga d'aplicacions trobarem aplicacions amb diferents modalitats d'adquisició: compres integrades, gratuïtes amb publicitat, gratuïtes sense publicitat que de vegades compten amb un contingut limitat anomenat versió lite o reduïda i, per últim, ofertes especials i rebaixes.

3. Seguretat. Valorarem positivament la possibilitat d'establir un control parental que regule l'ús de l'aplicació i del dispositiu mitjançant accions com codis o preguntes adaptades a l'edat de l'usuari que ens permeten controlar el menú de l'aplicació i bloquejar l'opció de realitzar compres.

4. Confidencialitat $i$ privacitat. L'aplicació ha d'explicar de forma clara $\mathrm{i}$ concisa la seua política de privacitat, a més ha de garantir l'anonimat i privacitat de dades dels seus usuaris: (noms, adreces, telèfons, adreces de 
correu, ubicació des d'on aquest es connecta). També ha d'oferir eines de suport com l'adreça electrònica del desenvolupador o el seu web.

5. Popularitat. Aquest és potser, el paràmetre més conflictiu de l'anàlisi i és que ens trobem amb un gran buit divulgatiu en aquest tipus de literatura. Ens centrarem en una perspectiva mixta i partirem de les crítiques publicades per Cristina Correro i Neus Real a la revista Faristol de forma mensual durant 2016 any.

6. Reconeixement professional. Com ocorria en l'apartat anterior de moment el context està buit, sense gran varietat de premis atorgats a aplicacions, de moment només comptem amb segells de qualitat com el de la millor aplicació a la Fira del Llibre de Bolonya (http://bookfaig.bolognafiere.it/). Tampoc trobem suports institucionals remarcables a excepció de casos puntuals, com assenyalarem més endavant.

7. Usabilitat. En aquest cas, pararem atenció al correcte funcionament de l'aplicació i ens centrarem especialment en la velocitat de reacció (que en cap cas ha de superar els 20-25 segons), la navegació amb icones identificables per als lectors-usuaris i la presència d'elements d'ajuda com instruccions d'ús i guies didàctiques.

8. Ergonomia. Posarem especial atenció a la llegibilitat, la claredat i l'ús del color per atraure a l'usuari-lector i facilitar l'ús i accés a l'aplicació.

Seguint l'esquema plantejat anteriorment ens trobem que són paràmetres de contingut:

1. Autoria. Conèixer l'editor i el desenvolupador de l'aplicació, així com el nom de totes les persones que han col·laborat en el seu procés de creació $i$ manteniment, el seu web i les seues xarxes social ens ajudarà a determinar el prestigi, el grau de reconeixement i l'especialitat de l'empresa desenvolupadora o editorial.

2. Actualització. La data de creació de l'última versió, així com l'historial de versions i la incorporació de nous títols són factors rellevants a l'hora de realitzar la compra d'una aplicació, ja que ens informaran de les seues millores i de l'ampliació dels seus continguts perquè no tinguen cap problema de funcionament. Cal tindre en compte que les versions antigues 
poden produir problemes en els dispositius i fins i tot interrompre el seu funcionament.

3. Continguts. Com que les aplicacions de lectura són paquets de llibres enriquits, pararem atenció en la diversitat de temes i gèneres dins del mateix paquet. En cas que l'objecte d'anàlisi siga un llibre app ens centrarem en la diversitat de continguts creats pel mateix desenvolupador.

4. Accessibilitat. Observarem si hi ha facilitat per realitzar cerques en la botiga segons el seu nom, categoria i edat dels usuaris, de si disposem d'informació sobre els títols i, sobretot, si ens permet la lectura sense connexió a Internet.

5. Organització de continguts. Aquest paràmetre està indicat per als paquets d'aplicacions on podem establir diversos tipus de visualització com un llistat o una llibreria que ens permeta organitzar els títols en carpetes, ordenar-los cronològicament per data de descàrrega i facilitar així la seua localització. Tindrem en compte la possibilitat de suprimir aquells que ja no volem i restaurar-ne en cas de voler-los recuperar.

6. Personalització de continguts: text (mida i tipus) brillantor de la pantalla, lectura a diverses pàgines; so (locució de la història o del mateix usuari); vídeo i animació, moviment dels objectes i dels personatges; possibilitat de realitzar cerques en els continguts $\mathrm{i}$ afegir anotacions (disponible per a usuaris a partir de 8 anys).

7. Interacció amb els continguts. Les apps ens permeten interactuar cap a fora de manera que l'usuari pot compartir informació mitjançant comentaris o valoracions de l'aplicació. Tanmateix, no podem oblidar que estem tractant amb aplicacions adreçades a menors i, per tant, cal cuidar la seua privacitat a les xarxes amb un control.

8. La qualitat de so. Pararem atenció en els efectes de so, la banda sonora i, especialment, a les característiques de la veu del narrador: modulació, veu neutra, entonació regional i dramatització, a més de la possibilitat de canviar la llengua de locució.

9. La interactivitat és el paràmetre que més cal tindre en compte. Les 7aplicacions treballen l'habilitat lectora mitjançant la gamificació i per això hem d'avaluar si aquest factor està equilibrat en el seu ús. Ens fixarem en la 
possibilitat de personalitzar les imatges, en els vídeos de suport al text, en les llistes de continguts i, sobretot, en els efectes multimèdia de l'aplicació com l'activació mitjançant el moviment o el so.

Així, a partir d'aquests paràmetres, i seguint el criteri d'avaluació d'aplicacions de lectura i llibres app de García-Rodríguez i Gómez-Díaz (2015) procedirem a fer la tria i posterior anàlisi.

\section{L'anàlisi d'aplicacions}

A l'hora de fer la selecció d'aplicacions de lectura i llibres app, partíem d'un context escàs amb una mancança d'informació i d'experiències, juntament amb poca promoció $i$ divulgació d'aquest nou gènere. Per elaborar-ne el corpus d'anàlisi, utilitzarem quatre referents clau que completarem amb els resultats d'una cerca personal: Celaya (2014), García-Rodríguez (2012), García-Rodríguez i Gómez-Díaz (2015) i les crítiques pioneres en català fetes durant els primers mesos del 2016 a la revista Faristol del Consell Català del Llibre Infantil i Juvenil, concretament als números 83 i 84 (Correro i Real, 2016).

Un altre factor que tenim en contra és la limitació del corpus d'estudi a aplicacions que comptaren, com a mínim, amb una versió en català, fet que en restringia els resultats. Les aplicacions de lectura i els llibres app són un nou gènere que, paradoxalment, es reinventa constantment i evoluciona a poc a poc però cada novetat suposa un canvi que deixa enrere la versió anterior, cosa que suposa un cert risc per a desenvolupadors i editors. En conseqüència, propostes com l'adaptació de les obres de Dickens, Doyle o Poe de l'empresa desenvolupadora iClassics (iClassics, 2012) van quedar fora d'estudi i és que, en paraules de Naiara Chaler (2016), Community Gardender de l'empresa, quan es planteja la possibilitat de crear una aplicació de lectura: «siempre empiezas por aquelles acciones que puedan tener un mayor impacto» i, malauradament el català queda emmudit enmig de la resta de llengües per la manca de demanda provocada per l'absència divulgativa i promocional de les apps. Ara bé, també ens trobem amb propostes pròpies que guanyen seguidors dia a dia a la xarxa com L'univers poètic de Miquel Martí i Pol o Un món de poesia de Joana Raspall les quals van nàixer amb la voluntat de trencar barreres entre la literatura i l'infant i, especialment, en la producció literària $\mathrm{i}$ cultural pròpia $\mathrm{i}$ que fins $\mathrm{i}$ tot ha arribat $\mathrm{a}$ 
convertir-se en un recurs per a treballar la poesia a l'aula. Així doncs, les tretze aplicacions i llibres app que conformen el corpus d'anàlisi són:

Taula 1. Descripció del corpus d'anàlisi

\begin{tabular}{|c|c|c|c|c|c|}
\hline ID & APP & DESENVOLUPADOR & VERSIÓ & CONTINGUT & EDAT \\
\hline $\begin{array}{l}\text { APP } \\
01\end{array}$ & $\begin{array}{l}\text { L'univers } \\
\text { poètic de } \\
\text { Miquel Martí } \\
\text { i Pol }\end{array}$ & Estudi Dada SL & 1.1 & Poesia & +4 anys \\
\hline $\begin{array}{l}\text { APP } \\
02\end{array}$ & $\begin{array}{l}\text { Un món de } \\
\text { poesia }\end{array}$ & $\begin{array}{l}\text { Ernest Cauhé i Tics } \\
\text { Mediàtics }\end{array}$ & 1.1 & Poesia & $\begin{array}{l}+4 \\
\text { Recomanada } \\
6-8 \text { anys }\end{array}$ \\
\hline $\begin{array}{l}\text { APP } \\
03\end{array}$ & $\begin{array}{l}\text { Els nens de la } \\
\text { meva escala }\end{array}$ & $\begin{array}{l}\text { Criteri digital i multimèdia } \\
\text { SL }\end{array}$ & 1.0 & Àlbum digital & +4 anys \\
\hline $\begin{array}{l}\text { APP } \\
04\end{array}$ & $\begin{array}{l}\text { Carmesina - } \\
\text { The Guardian } \\
\text { of } \\
\text { Imagination }\end{array}$ & Play Creatividad & 1.6 & $\begin{array}{l}\text { Distòpia. Contes } \\
\text { amb valors }\end{array}$ & $\begin{array}{l}+4 \\
\text { Recomanada } \\
9-11 \text { anys }\end{array}$ \\
\hline $\begin{array}{l}\text { APP } \\
05\end{array}$ & $\begin{array}{l}\text { Yo mataré } \\
\text { monstruos por } \\
\text { ti }\end{array}$ & Raul Soler & 1.5 & Conte de bressol & $\begin{array}{l}+4 \\
\text { Recomanada } \\
6-8 \text { anys } \\
\end{array}$ \\
\hline $\begin{array}{l}\text { APP } \\
06\end{array}$ & $\begin{array}{l}\text { El baúl de los } \\
\text { Monstruos }\end{array}$ & Itbook Editorial & 1.3 & Contes de terror & +4 anys \\
\hline $\begin{array}{l}\text { APP } \\
07\end{array}$ & $\begin{array}{l}\text { Sant Jordi, la } \\
\text { llegenda }\end{array}$ & Kiriam Angles Gonzales & 2.2 .0 & $\begin{array}{l}\text { Conte popular. } \\
\text { llegenda }\end{array}$ & +4 anys \\
\hline $\begin{array}{l}\text { APP } \\
08\end{array}$ & $\begin{array}{l}\text { Emotions } \\
\text { collection }\end{array}$ & Itbook Editorial & 1.1 & $\begin{array}{l}\text { Contes amb } \\
\text { valors }\end{array}$ & $\begin{array}{l}+4 \\
\text { Recomanada } \\
3-8 \text { anys }\end{array}$ \\
\hline $\begin{array}{l}\text { APP } \\
09\end{array}$ & $\begin{array}{l}\text { Contes } \\
\text { clàssics | } \\
\text { Cuentos } \\
\text { clásicos }\end{array}$ & La Caixa & 1.3 .1 & Conte popular & +4 anys \\
\hline $\begin{array}{l}\text { APP } \\
10\end{array}$ & $\begin{array}{l}\text { Li'l Red - An } \\
\text { interactive } \\
\text { Story }\end{array}$ & Brian Main & 1.03 & $\begin{array}{l}\text { Llibre visual. } \\
\text { Conte popular }\end{array}$ & +4 anys \\
\hline $\begin{array}{l}\text { APP } \\
11\end{array}$ & $\begin{array}{l}\text { Three little } \\
\text { pigs Lite - } \\
\text { Playbook }\end{array}$ & Multiactiva Mobile & 1.0 & Conte popular & +4 anys \\
\hline $\begin{array}{l}\text { APP } \\
12\end{array}$ & $\begin{array}{l}\text { Cindirella } \\
\text { HD. Itbook } \\
\text { story-toy }\end{array}$ & Itbook Editorial & 1.1 & Conte popular & +4 anys \\
\hline $\begin{array}{l}\text { APP } \\
13\end{array}$ & $\begin{array}{l}\text { The tortoise } \\
\text { and the hare. } \\
\text { Itbook story- } \\
\text { toy }\end{array}$ & Itbook Editorial & 1.1 & Conte popular & +4 anys \\
\hline
\end{tabular}




\section{Resultats de l'anàlisi i conclusions}

Les aplicacions i llibres apps seleccionats ens han conduït a diferents problemes d'anàlisi que ha fet que ens replantegem els paràmetres i les taules d'avaluació establertes per Garcia-Rodríguez i Gómez-Díaz (2015). Seguint aquesta proposta i una vegada portat a terme aquest procés, aportarem els resultats i matisos d'anàlisi, que trobem esquematitzat a la Figura 4.
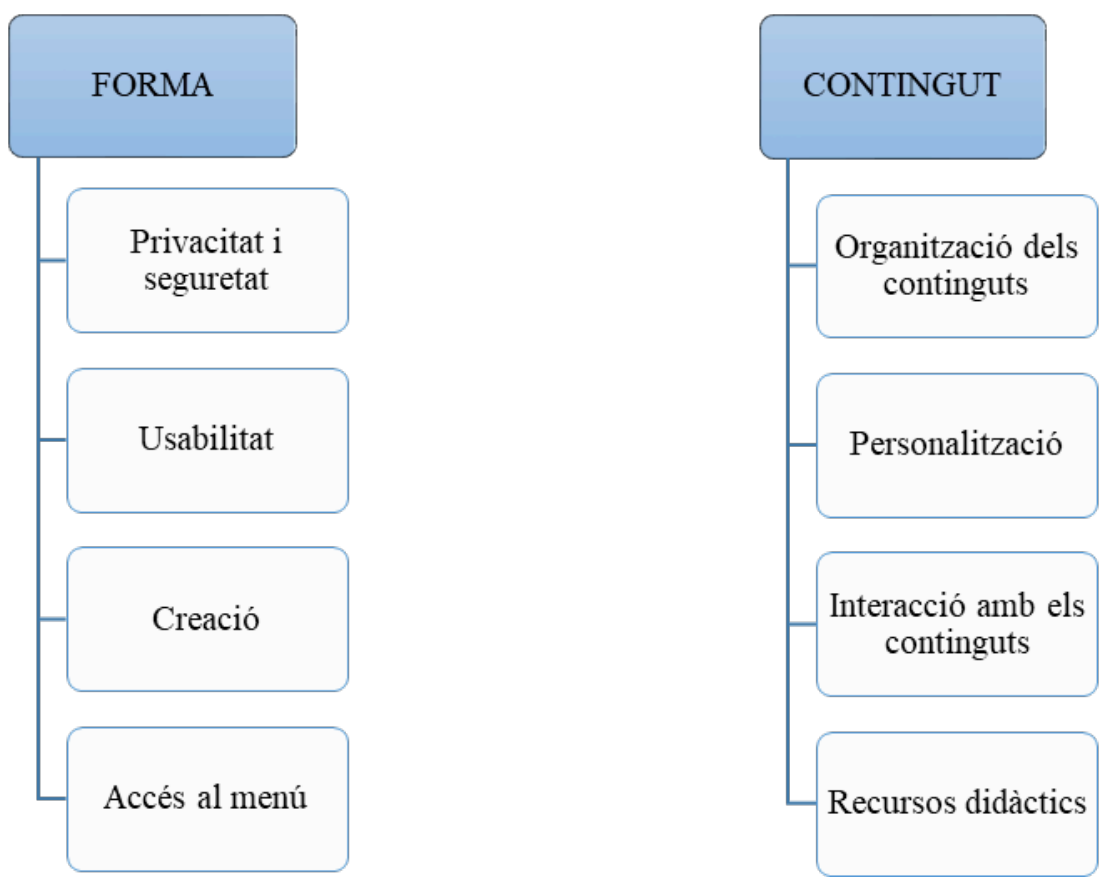

Figura 4. Matisos en l'anàlisi d'aplicacions i llibres app. Font: Elaboració pròpia

\section{Dimensió forma}

a) Privacitat $i$ seguretat. És el punt més important que cal tenir en compte a l'hora de comprar una aplicació perquè que com a consumidors, hem de tenir garantit el nostre anonimat i la confidencialitat de totes les dades a què l'aplicació tinga accés cuidant així, la protecció de dades (Llei Orgànica 15/1993 i Real Decret 428/1993). Durant l'anàlisi de les aplicacions hem observat que només quatre de les tretze apps analitzades aporten informació sobre com el desenvolupador garanteix la privacitat de l'usuari. Tanmateix sí que trobem la possibilitat que el sistema operatiu del lector electrònic utilitzat (tant iOs com Android) sol·licite accés a l'hora d'utilitzar un recurs com bé pot ser la càmera o les coordenades geogràfiques del nostre dispositiu, en cas que l'usuari no accepte aquest accés, l'aplicació pot seguir funcionant normalment però, no debades hem de tenir en 
compte que amb un simple toc de dit per confirmar o rebutjar aquest permís no es pot aturar un infant, per això és molt important l'existència d'un control parental adaptat a l'edat del menor com el que trobem a l'Aplicació 4, on l'accés al menú i a la configuració de l'aplicació rau en la solució d'una operació matemàtica.

b) Usabilitat. Cal anar més enllà d'una obertura ràpida i una navegació senzilla. Cal destacar que l'aplicació compte amb una presentació a manera d'introductio tematis que ens indique que trobarem en el seu contingut, quin tipus de llibres conté o quin és el fil connector que hi ha entre ells. Aquesta característica és molt important per a presentar la lectura i apropar-la encara més a l'infant. No obstant això, només la trobem en tres de les tretze aplicacions.

- Aplicació 1. El poeta Miquel Martí i Pol se'ns presenta amb uns versos:

«Visc en un poble petit,/ en un país petit/ i, tanmateix, vull que quedi ben clar/ que això que escric ho escric per a tothom,/ i que per mi és com si el món sencer/girés entorn de l'eix dels meus poemes»

- Aplicació 2. Quan iniciem l'aplicació, el desenvolupador ens planteja el menú de continguts com un planeta blau amb arbres en què és de nit i trobem els apartats del món de poesia de Joana Raspall (Figura $5)$. 


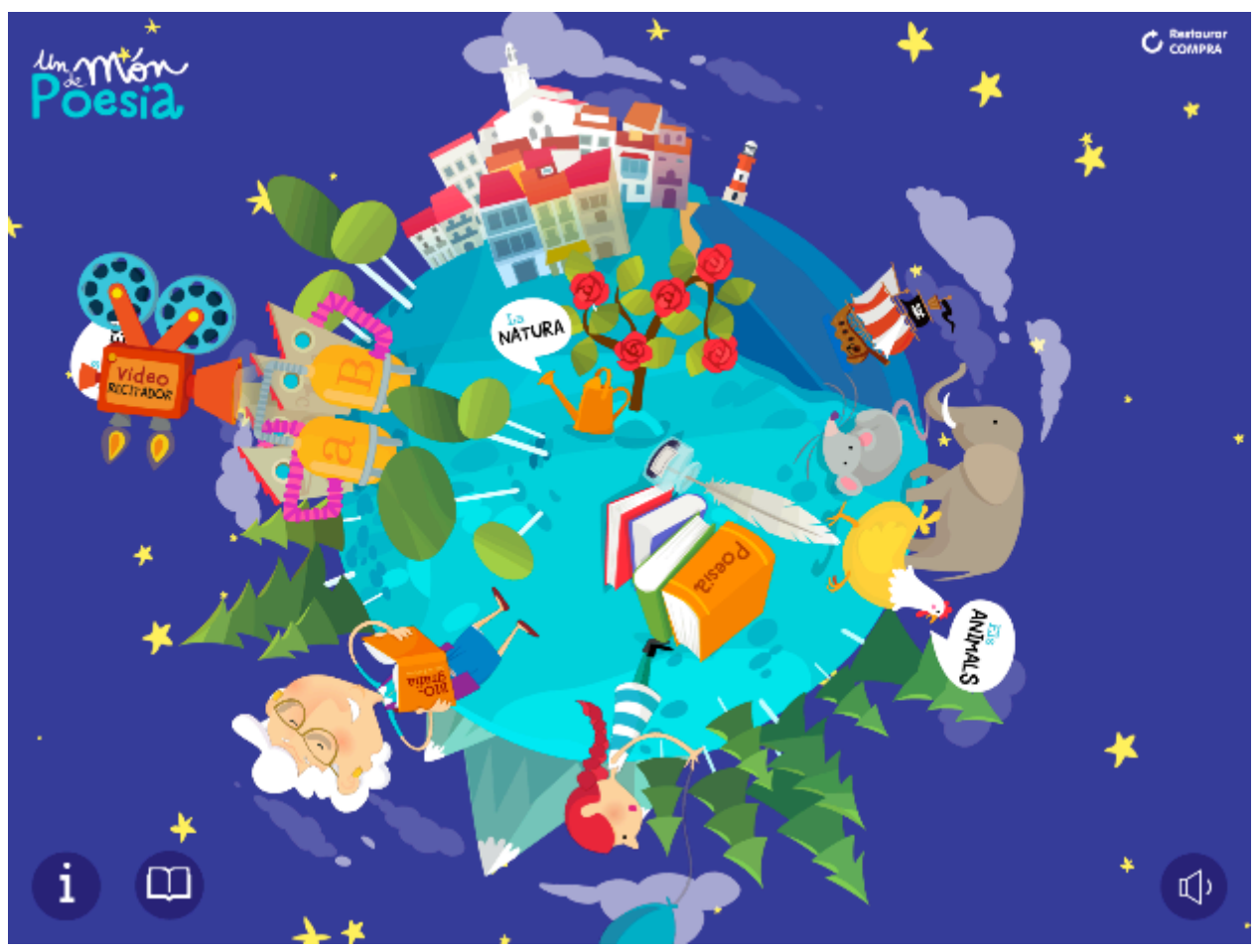

Figura 5. Font: Un món de poesia d'Ernest Cahué i TICS Mediàtics

- Aplicació 4. Des d'un inici, l'aplicació ens conta la història de la protagonista, Carmesina i el lector coneix la història dels cofres de la memòria des de l'inici.

c) Creació. A mesura que analitzàvem les diferents versions de les apps, ens van trobar amb casos on tot i tenir més d'un any encara estan en la primera o segona versió que no ha suposat cap mena de millora. Caldria modificar-ne els paràmetres $\mathrm{i}$ incloure aquest factor per a valorar els possibles problemes que podrien afectar el dispositiu.

d) Accés al menú des de totes les pàgines. És un recurs imprescindible. Serveix per a facilitar-ne l'accés als continguts, especialment als primers lectors. Malauradament, no el trobem a totes les aplicacions, cosa que dificulta una mica la lectura d'aquelles que no el tenen. Un exemple de bona pràctica és el disseny creat per Itbook, que permet l'accés a totes les pàgines del conte, a la configuració de l'aplicació, als jocs i a la llibreria del desenvolupador (Figura 6). 


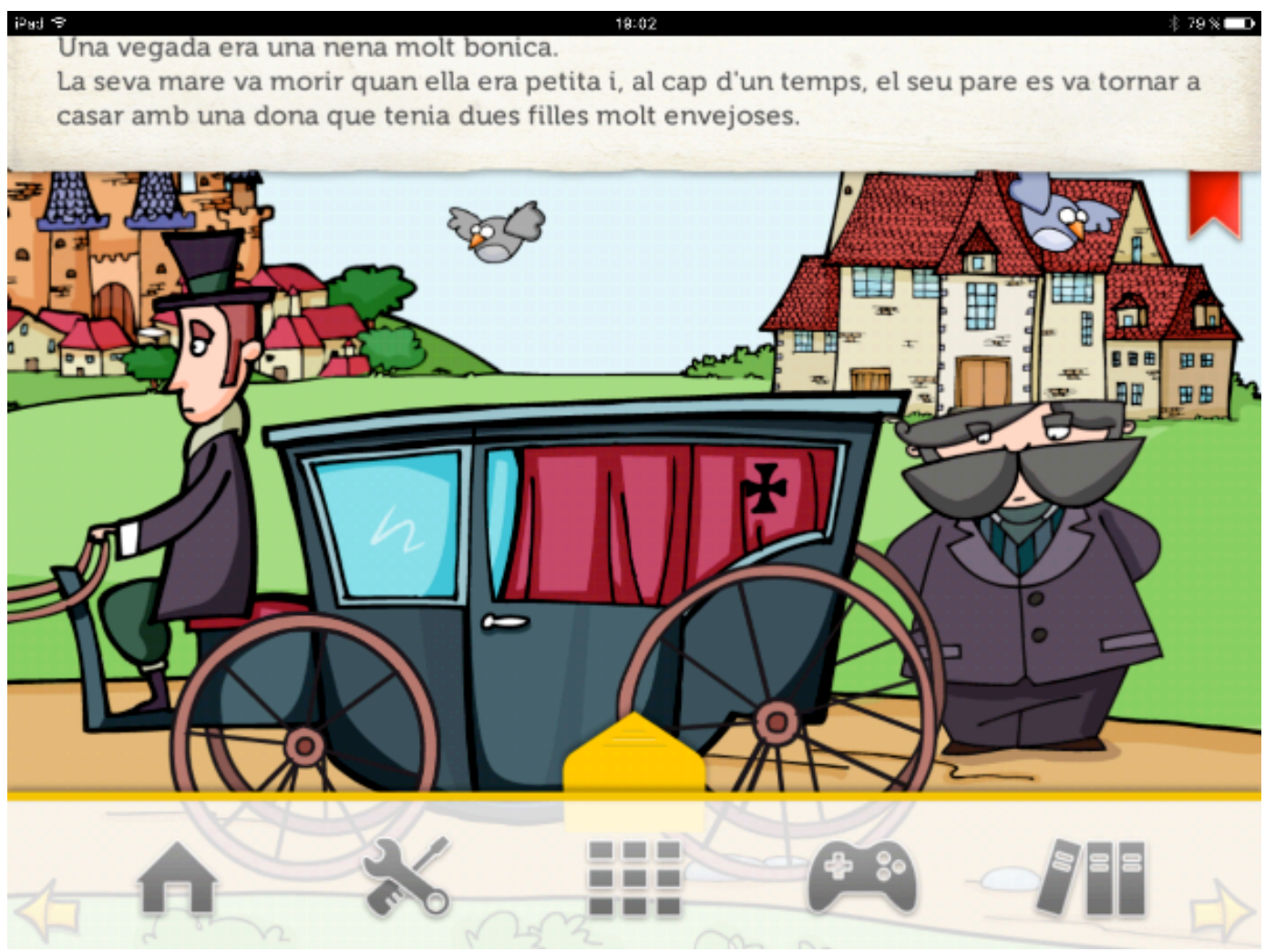

iPys 9

19:02
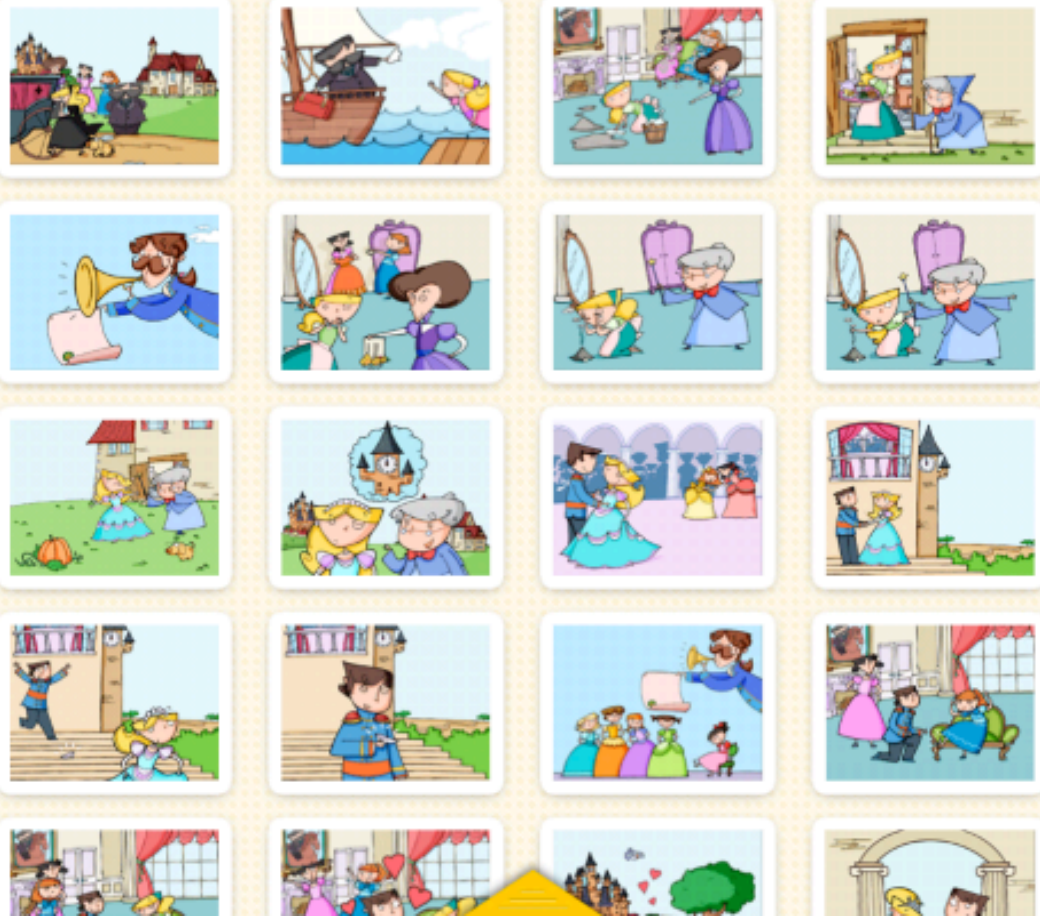

Figura 6. Font: Cindirella HD. Itbook story-toy d'Itbook Editorial 


\section{Dimensió contingut}

a) Organització dels continguts. Cap de les cinc aplicacions de lectura analitzades permet organitzar els continguts en carpetes o canviar l'ordre en què les trobem a la prestatgeria (aplicacions 2, 3, 6, 8 i 9) i només permeten la possibilitat de restaurar les compres realitzades en cas de voler recuperar algun dels llibres app descarregats anteriorment.

b) Personalització. Aquest punt analitza:

- La narració oral i els sons de les animacions. En alguns casos l'aplicació permet activar i desactivar $\mathrm{i}$ en altres (aplicacions 6, 8, 12 i 13) gravar la nostra narració dramatitzada, fet que afavoreix la lectura i caldria valorar més positivament dins dels paràmetres proposats.

- El text. La mida i la tipologia del text hauria de ser valorable i no només a partir dels 8 anys com indiquen les autores en els seus paràmetres, atès que els primers lectors poden necessitar graduar el text en funció del seu progrés lector.

- Realització de cerques en el contingut i anotacions. Aquest paràmetre i els resultats obtinguts ens planteja interrogants si realment cal apostar per crear enllaços externs a les aplicacions dins del seu contingut, tal com ho faríem amb un llibre electrònic per a e-reader. De les tretze aplicacions analitzades només ens hem trobat amb una (Aplicació 4) adreçada per a majors de 8 anys, edat en què segons les autores, aquest recurs és recomanable i, tanmateix el desenvolupador no ho considera necessari.

c) Interacció amb els continguts. No totes les aplicacions tenen com a finalitat que els lectors entren per complet en els bucles d'interactivitat per a participar en la història $\mathrm{i}$ en molts casos ens trobem amb un excés de gamificació i animacions que arriben a distraure'ls de la lectura. Cal assenyalar-ne quatre que sí que assoleixen els nivells d'interactivitat de Teixes (2014).

- Aplicació 4. Una vegada presentada la història de Carmesina. el lector, aconseguidor, haurà de completar les lectures de cada conte encofrat per aconseguir la clau que obrirà el següent i així descobrir els secrets del Magatzem de la memòria dels habitants de La ciutat dels colors oblidats. 
- Aplicació 2. Dins del món proposat sobre la poesia de Joana Raspall, ens trobem amb un lector aconseguidor que ha de desxifrar diverses proves. Trobem reptes sobre el vocabulari que apareix als poemes de la poetessa mitjançant activitats mnemotècniques, fer jocs de paraules, caçar paraules voladores, jugar a trobar la imatge que fa parella amb cada mot per aconseguir així desbloquejar els seus poemes.

- Aplicació 1. Un lector explorador que ha de localitzar les il·lustracions amagades rere les quatre estacions de l'any en què trobarem els poemes de Miquel Martí i Pol, el videorecitador o jocs de paraules.

- Aplicació 10. Lil' Red és un exemple de lector explorador i és que, enmig d'un conte en blanc i negre, el lector ha de seguir animacions amb elements de color roig que esdevenen el fil conductor de la història per a completar la lectura (Figura 7).

d) Recursos didàctics. Les aplicacions també poden anar adreçades al món educatiu i ajudar així a l'alfabetització de l'infant però, si anem més enllà, fins i tot poden contribuir al seu desenvolupament, com és el cas de l'Aplicació 8, on el desenvolupador ens planteja diverses propostes per a treballar a l'aula emocions com l'alegria, la por o la preocupació. 


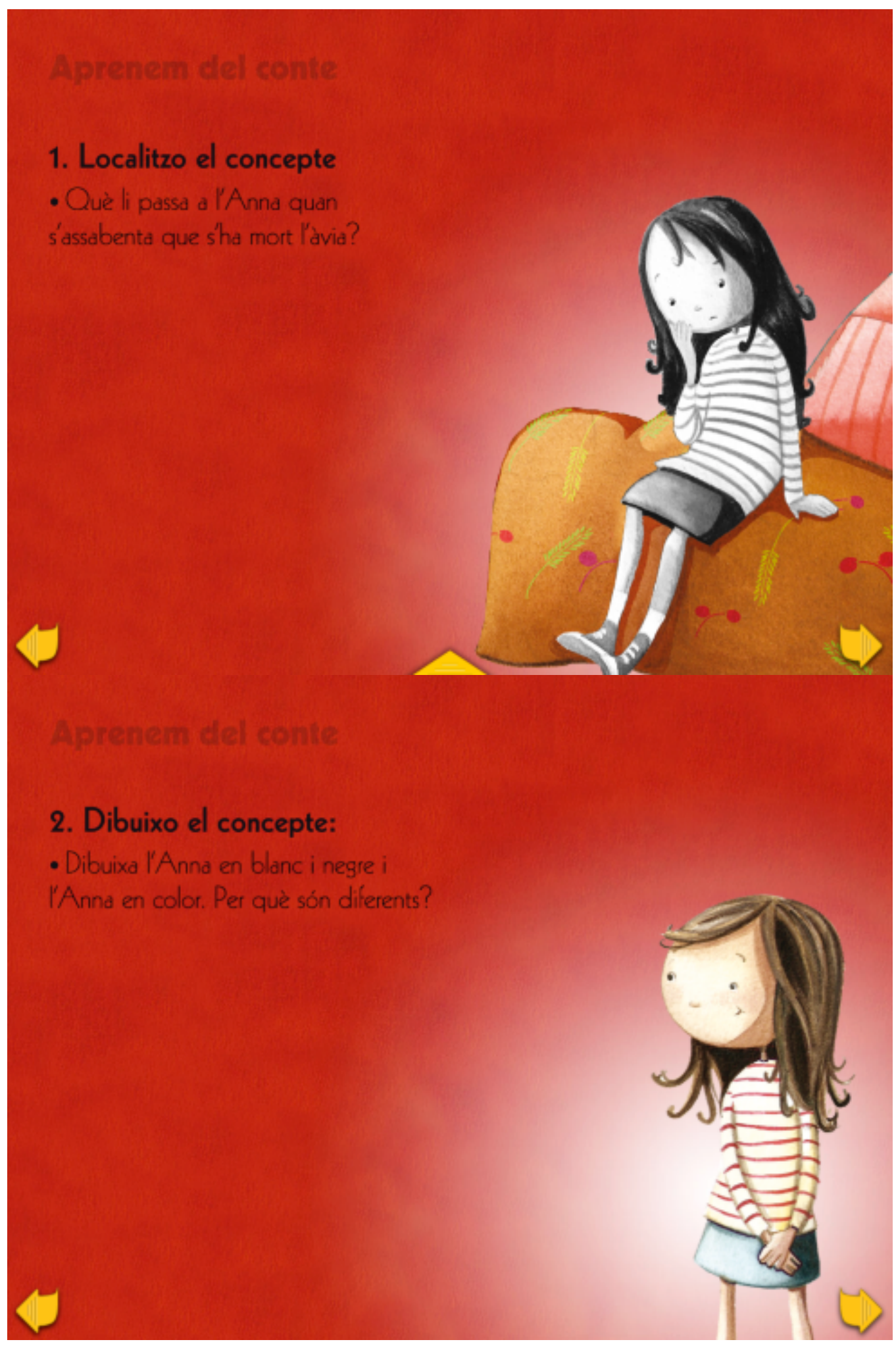




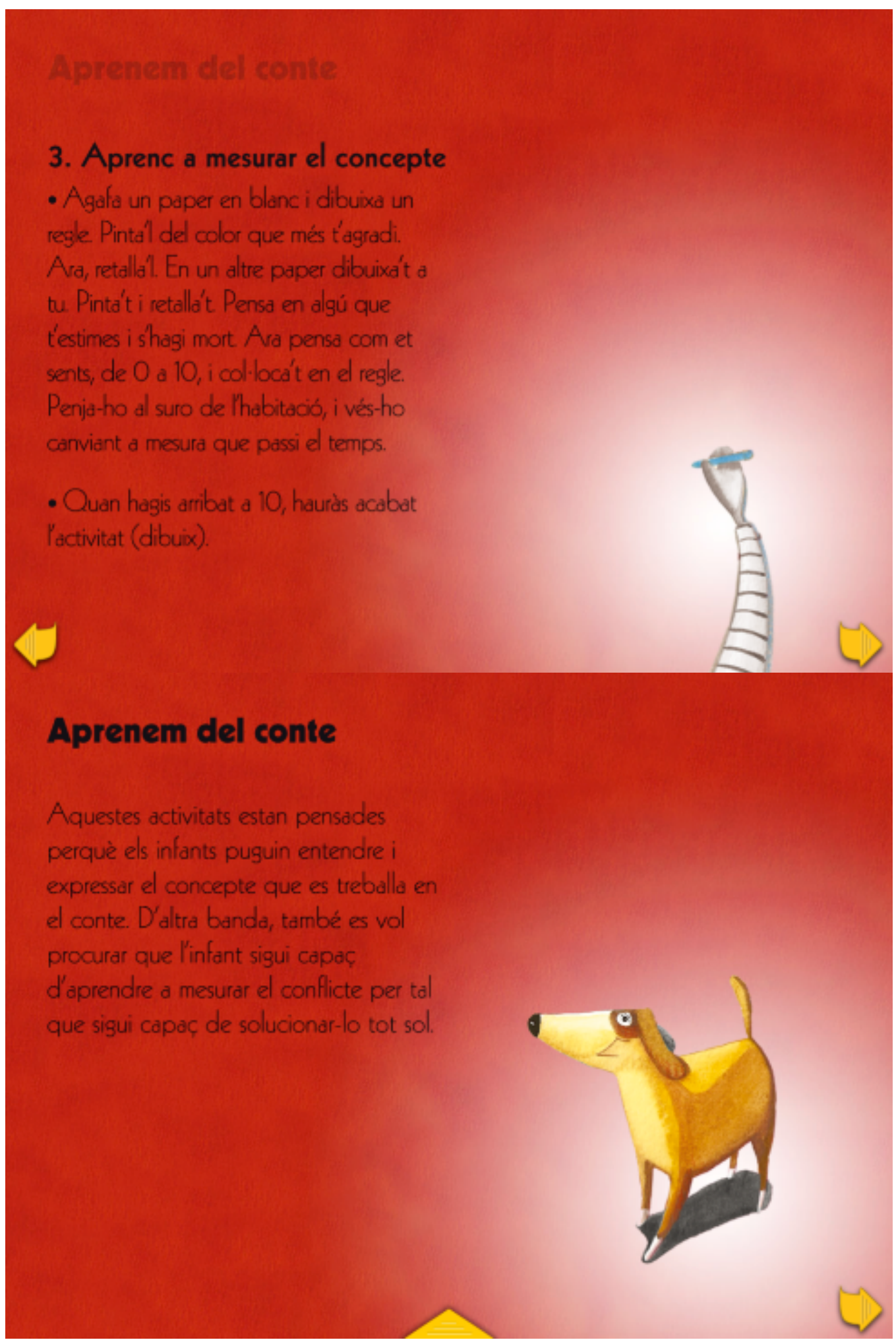

Figura 7. Font: Emotions collection d'Itbook Editorial 


\section{Per a la discussió}

En finalitzar la presentació dels resultats de la recerca retornem a l'interrogant inicial: els paràmetres utilitzats són els adequats? Al llarg de l'anàlisi de les tretze aplicacions ens hem trobat amb un inconvenient $\mathrm{i}$ és que els paràmetres necessiten precisar el grau de plasticitat que poden arribar a tenir les aplicacions i la facilitat per a esdevindre nous tipus de literatura digital. Així, apareixen casos com l'Aplicació 10, Lil' Red, que es tracta d'un conte visual sense cap mena de narració on qui construeix i lliga el fil de la història és el lector. Aquesta aplicació és un dels millors llibres amb què ens hem trobat en l'anàlisi però, com que es tracta d'una proposta visual, perd valor si el valorem amb els paràmetres de Garcia-Rodríguez i Gómez-Díaz (2015), ja que com hem esmentat, no compta amb cap suport de text ni amb una narració amb què interactuar. Un altre tipus d'aplicació que ix perjudicada amb els paràmetres d'anàlisi assenyalats és l'àlbum digital, atès que, a més de comptar amb nivells d'interactivitat molt baixos, tampoc ens ofereix una gran capacitat de personalització. Si més no, en aquestes propostes les il·lustracions són el punt fort i, en cas de modificar-les en excés, s'alteraria la història per complet i perdria el seu sentit.

Aquests entrebancs ens condueixen a més interrogants encara. Com hem anat assenyalant al llarg de tot el treball, les aplicacions avancen molt a poc a poc però cada pas pot comportar la gran innovació $\mathrm{i}$ hem d'estar alerta. Necessitem uns paràmetres consensuats per a poder així facilitar-ne la selecció i distingir les aplicacions de lectura i llibres app més adequades d'aquelles més atractives amb continguts no recomanables per als infants. És per això que ens quedem amb la idea que cal seguir treballant en aquest repte per a tenir uns criteris plàstics ben definits que s'adeqüen correctament a cada tipus de gènere i continguts: poesia, narrativa, àlbum il·lustrat..., sense deixar de banda les relacions que apareixen entre les diferents aplicacions i, especialment, el fet que aquest nou tipus de literatura infantil i juvenil digital ens ajuda a trencar les barreres que hi ha entre literatura $\mathrm{i}$ infant perquè impliquen al lector-usuari en la història $\mathrm{i}$, alhora, el converteix en protagonista. Si més no, no podem oblidar que és la finalitat bàsica d'aquest tipus de literatura.

\section{Agraïments}

Article elaborat en el marc del projecte d'investigació «Los espacios virtuales para la promoción del libro y la lectura. Formulación de indicadores para evaluar su calidad y 
efectividad» FFI2015-69977-R (MINECO/FEDER), Proyectos I+D+I del Programa Estatal de Investigación, Desarrollo e Innovación. Ministerio de Economía y Competitividad de España. Convocatòria 2015.

\section{Referències}

Aliagas Marín, C., i Margallo, A. M. (2014). ¿Cómo transforma el Ipad las prácticas lectoras literarias? Un estudio etnográfico sobre los efectos del soporte digital en las experiencias de lectura infantil en el contexto familiar. En M. F. Moscoso Rosero (ed.), Etnografia de la socializacion en las familias (p. 25-32). Madrid: Traficantes de sueños.

Aliagas Marín, C., i Margallo, A. M. (2015). iPads, emergent readers and families. En Manresa i Real (eds.), Digital literature for children. Texts, readers and educational practices (p. 155-171). Brussel-les: Peter Lang. DOI: https://doi.org/10.3726/978-3-0352-6577-4/22

Báez Montero, I. C., i Suárez Rodríguez, B. P. (2011). Lectura analógica/lectura digital: «El papel» de las lecturas graduadas en aprendices de E/LE. En C. Hernández González, A. Carrasco Santana, i E. Álvarez Ramos (eds.), La Red y sus aplicaciones en la enseñanza-aprendizaje del español como lengua extranjera (p. 117-128). Valladolid: Asociación para la Enseñanza del Español como Lengua Estrangera.

Celaya, J. (2014). Apps educativas. Madrid: Dosdoce.

Chaler, N. (05 d'abril del 2016). Aplicaciones de clásicos [Missatge en llista de distribució electrònica]. Recuperat de press@iclassicscollection

Colomer, T. (2010). Introducción a la literatura infantil y juvenil actual. Madrid: Síntesis.

Correro, C., i Real, N. (2014). Literatura infantil digital 0-6. Present i futur. Faristol, 79, 3-7. Recuperat de http://www.clijcat.cat/faristol/descargas/79/1_79.pdf

Correro, C., i Real, N. (2016). Els nens de la meva escala. Faristol. Recuperat de http://www.clijcat.cat/faristol/paginas/detall_critiques.php?recordID $=2820$

Correro, C., i Real, N. (2016). L’univers poètic de Miquel Martí i Pol. Faristol. Recuperat de http://www.clijcat.cat/faristol/paginas/detall_critiques.php?recordID $=2840$ 
Correro, C., i Real, N. (2016). Lil' Red - An Interactive Story. Faristol. Recuperat de http://www.clijcat.cat/faristol/paginas/detall_critiques.php?recordID=2795

Correro, C., i Real, N. (2016). Sant Jordi, la llegenda. Faristol. Recuperat de http://www.clijcat.cat/faristol/paginas/detall_critiques.php?recordID $=2839$

Correro, C., i Real, N. (2016). Un món de poesia. Faristol. Recuperat de http://www.clijcat.cat/faristol/paginas/detall_critiques.php?recordID $=2814$

Flewitt R., Messer D., i Kucirkova N. (2015). New directions for early literacy in a digital age: The iPad. Journal of Early Childhood Literacy, 15, 289-310. DOI: https://doi.org/10.1177/1468798414533560

García-Rodríguez A., i Gómez-Díaz, R. (2015). Las demasiadas aplicaciones: parámetros e indicadores para seleccionar las TOPAPP de lectura para ninos. Anales de Documentación, 18(2). DOI: http://dx.doi.org/10.6018/analesdoc.18.2.227071

García-Rodríguez, A. (2012). Diagnóstico del mercado de contenidos digitales infantiles y juveniles en España. En J. A. Cordón García, F. Carbajo Cascón, R. Gómez Díaz, i J. Alonso Arévalo (eds.), Libros electrónicos y contenidos digitales en la sociedad del conocimiento (p. 129-157). Madrid: Pirámide.

García-Rodríguez, A., i Gómez-Díaz, R. (2016). Lectura digital infantil. Dispositivos, aplicaciones y contenidos. Barcelona: UOC.

Gómez-Díaz, R., i Cordón-García, J. A. (2015): DINLE, Diccionario Digital de nuevas formas de lectura y escritura. Salamanca: Universidad de Salamanca. Red Internacional de Universidades Lectoras. Recuperat de http://dinle.usal.es/searchword.php?valor=Aplicaciones\%20de\%20lectura

iClassics (2012). IPoe: The interactive and illustrated Edgar Allan Poe. Versió 3.2.1.

Recuperat de http://iclassicscollection.com/en/project/ipoe1/

Ley Orgánica 15/1999, de 13 de diciembre, de Protección de Datos de Carácter Personal, BOE, núm. 298, 14-12-1999. Última modificació: 15 de març de 2011. Recuperat de https://www.boe.es/buscar/act.php?id=BOE-A-1999-23750

Lluch, G. (2010). Cómo seleccionar libros para niños y jóvenes. Los comités de valoración en las bibliotecas escolares y públicas. Gijón: Trea.

Lluch, G. (2011). La llegenda dels nadius digitals. Gemma Lluch. Recuperat de http://www.gemmalluch.com/la-llegenda-dels-nadius-digitals/ 
Lluch, G. (2015). Los criterios de selección de libros digitales. Gemma Lluch.

Recuperat de http://www.gemmalluch.com/esp/los-criterios-de-seleccion-delibros-digitales/

Meyers, E. M., Zaminpaima, E., i Frederico, A. (2014). The future of children's texts: Evaluating book apps as multimodal reading experiences. iConference 2014 Proceedings (p. 916-920). DOI: https://doi.org/10.9776/14312

Ministerio de Educación, Cultura y Deporte (2015). Encuesta de hábitos y prácticas culturales en España 2014-2015. Recuerat de https://www.mecd.gob.es/dam/jcr:a185d7f5-0331-4f8c-90be52b6d4991040/encuesta-de-habitos-y-practicas-culturales-2014-2015-sintesis-deresultados.pdf

Observatorio de la Lectura y del Libro, i el Ministerio de Educación, Cultura y Deporte (2015). Informe del sector del libro en España (2013-2015). Recuperat de http://www.mecd.gob.es/dms/mecd/cultura-mecd/areascultura/libro/mc/observatoriolect/redirige/estudios-e-informes/elaborados-por-elobservatoriolect/sector-libro-abril2015/sector-libro-abril2015.pdf

Real Decreto 428/1993, de 26 de marzo, por el que se aprueba el Estatuto de la Agencia de Protección de Datos, BOE, núm. 106, 4-5-1993. Última modificació: 5 de novembre de 2008. Recuperat de: https://www.boe.es/diario_boe/txt.php?id=BOE-A-1993-11252

Roca, G. (2012). Educació, participació i xarxes socials [vídeo]. Recuperat de http://www.uab.cat/videos/

Sanz Pilar, N., i García-Rodríguez, A. Los desarrolladores de libros app infantiles y juveniles: radiografía, perspectivas y modelo de negocio. Anales de Documentación, 17(2). DOI: http://dx.doi.org/10.6018/analesdoc.17.2.192131

Teixes, F. (2014). Gamificación: fundamentos y aplicaciones. Barcelona: Editorial UOC.

Turrión Penelas, C. (2014). Electronic literature for children. Characterising narrative apps (2010-2014). Dins M. Manersa, i N. Real (eds.), Digital literature for children. Texts, readers and educational practices (p. 87-102). Brussel·les: Peter Lang. DOI: https://doi.org/10.3726/978-3-0352-6577-4/16 


\section{Annex}

\begin{tabular}{|c|c|}
\hline APLICACIÓ 1 & $\begin{array}{l}\text { EstUdi DADA SL (2016): L'univers poètic de Miquel Martí } i \\
\text { Pol. Versió 1.1, març 2016. }\end{array}$ \\
\hline APLICACIÓ 2 & $\begin{array}{l}\text { ERNEST CAUHÉ, TICS MEDIÀTICS (2015): Un món de poesia. } \\
\text { Versió 1.1, gener } 2016 .\end{array}$ \\
\hline APLICACIÓ 3 & $\begin{array}{l}\text { CRITERI Digital I Multimedia SL (2015): Els nens de la } \\
\text { meva escala. Versió 1.0, juliol } 2015 \text {. }\end{array}$ \\
\hline APLICACIÓ 4 & $\begin{array}{l}\text { Play CREATIVIDAD (2015): Carmesina - The Guardian of } \\
\text { Imagination HD. Versió 1.6, febrer } 2015 .\end{array}$ \\
\hline APLICACIÓ 5 & $\begin{array}{l}\text { RAUL SOLER (2014): Yo mataré monstruos por ti. Versió 1.5, } \\
\text { maig } 2014 .\end{array}$ \\
\hline APLICACIÓ 6 & $\begin{array}{l}\text { ITBOOK EDITORIAL (2013): El baúl de los Monstruos. Versió } \\
1.3 \text {, octubre } 2013 \text {. }\end{array}$ \\
\hline APLICACIÓ 7 & $\begin{array}{l}\text { KIRIAM ANGLES GONZALES (2013): Sant Jordi, la llegenda. } \\
\text { Versió 2.2.0, abril } 2014 .\end{array}$ \\
\hline APLICACIÓ 8 & $\begin{array}{l}\text { ITBOOK EDITORIAL (2012): Emotions collection. Versió 1.1, } \\
\text { octubre } 2014 .\end{array}$ \\
\hline APLICACIÓ 9 & $\begin{array}{l}\text { LA CAIXA (2014): Contes clàssics | Cuentos clásicos. Versió } \\
\text { 1.3.1, març 2016. }\end{array}$ \\
\hline APLICACIÓ 10 & $\begin{array}{l}\text { BRIAN MAIN (2012): Li'l Red - An interactive Story. Versió } \\
\text { 1.03, febrer } 2013 .\end{array}$ \\
\hline APLICACIÓ 11 & $\begin{array}{l}\text { Multiactiva MoBiLe (2011): Three little pigs Lite - } \\
\text { Playbook. Versió } 1.0, \text { setembre } 2011 .\end{array}$ \\
\hline APLICACIÓ 12 & $\begin{array}{l}\text { ITBOOK EDITORIAL (2011): Cindirella HD. Itbook story-toy. } \\
\text { Versió 1.1, febrer } 2012 .\end{array}$ \\
\hline APLICACIÓ 13 & $\begin{array}{l}\text { ITBOOK EDITORIAL (2011): The tortoise and the hare. Itbook } \\
\text { story-toy. Versió 1.1, abril } 2012 .\end{array}$ \\
\hline
\end{tabular}




\section{Informació sobre l'autora}

Maria Peris Bixquert (Barxeta, 1994) és graduada en Filologia Catalana en la Universitat de València, on també ha realitzat el Màster en Professor de Secundària i el Màster en Assessorament Lingüístic i Cultura Literària: Aplicacions al Context Valencià. Actualment realitza la tesi doctoral "Aplicacions de lectura per a infants i joves. Anàlisi i proposta d'indicadors d'avaluació", dins el programa del Doctorat en Lectura i Comprensió i combina la investigació amb l'ensenyament.

Email: mapebix@alumni.uv.es

Per citar aquest article:

Peris Bixquert, M. (2018). Anàlisi crítica d'aplicacions de lectura per a infants: paràmetres i indicadors. Bellaterra Journal of Teaching \& Learning Language \& Literature, 11(3), 39-63. DOI: http://doi.org/10.5565/rev/jt13.734 